\title{
The rising politics of sea level: demarcating territory in a vertically relative world
}

\author{
Katherine G. Sammler \\ To cite this article: Katherine G. Sammler (2019): The rising politics of sea level: demarcating territory in a vertically \\ relative world, Territory, Politics, Governance, DOI: 10.1080/21622671.2019.1632219 \\ For citation, please go to published version of this article: https://doi.org/10.1080/21622671.2019.1632219 \\ CONTACT \\ ksammler@csum.edu \\ Department of Global Studies \& Maritime Affairs, California State University Maritime Academy, Vallejo, CA, USA.
}

\begin{abstract}
Sea level rise has destructive material impacts on coastal communities and low-lying nations. While it is largely perceived and experienced via these impacts, the level of the sea is less often thought about as a political surface. The boundary where land and sea intersect is determined by the ocean's height, manifesting materially as a realm of coastal features and produced politically as baselines. Defined through international treaties, baselines are the low-water line upon which national boundaries are traced. Yet, this line between adjoining mediums of land and sea is much more physically blurred and dynamic than represented politically and legally. The difficulties of delimiting a coastline, a phenomenon referred to as the Coastline Paradox, means the measurement of a coastline is dependent on the ruler used, an entanglement of instrument and measurement. As rising sea levels encroach on physical coastlines, they are also impacting legal baselines, shifting national terrestrial and maritime borders inland posing existential dilemmas to island and low-lying nations. This paper examines how the concept of sea level was constructed scientifically and is enrolled in the legal demarcation of territorial borders, with the goal of examining how sea level rise politically marks a climatically changing world.

KEYWORDS

sea level rise; baselines; territory; materiality; verticality; geopolitics
\end{abstract}

INTRODUCTION

Sea-level rise is not only a question of scientific uncertainty - it also entails extreme legal uncertainty.

(Houghton, Vafeidis, Neumann, \& Proelss, 2010, p. 816)

Sea level rise has entered mainstream consciousness through developing concerns over floods, erosion and major damage to coastal city infrastructure. While it is largely perceived and experienced via these impacts, sea level is less often thought about as a highly technical and political surface. The height of the ocean determines the boundary where land and sea meet and mix, manifesting materially as a realm of coastal features and produced politically as 'baselines' by means of technical practices. Legally codified by international treaties, baselines are the low-water line upon which political boundaries are traced. Coastlines 
are used to construct national and international borders over the Earth's surface, a horizontal delimitation, but as Stuart Elden establishes, '[w]e all-too- often think of the spaces of geography as areas, not volumes. Territories are bordered, divided and demarcated, but not understood in terms of height and depth' (Elden, 2013a, p. 35). Not only does the ocean's height determine coastal political boundaries but also the ocean's surface is the planer stratum from which demarcations of height and depth are measured. It serves as a global reference for elevation and altitude and therefore determining the limits of many territorial claims. For these reasons, sea level influences territoriality throughout the volume of land, sea and air that make up our globe.

Explicitly examining the conceptual formulation of sea level and the legal construction of base- lines, this paper expounds on one of Elden's proposed questions: 'How does the geopolitical take account of the geophysical?' (Elden, n.d.). This is done by analysing the tensions that arise when the averages of science encounter the precision of juridical delineation in dynamic coastal areas. Tracing how a level sea is conceived and employed, from the ocean's complex surface topography to a simplified plane, this paper challenges the idea that the foundation of borders and territories emerge from apolitical, 'natural' phenomena. Tracking the historical methods and instrumentation of accounting for height and depth presents alternating visions of surveying land from the sea and sea from the land, making explicit the relational terms of vertical territoriality. This allows for a reckoning of what is implicit in these evaluations, and how a zero-reference plane is determined and maintained. Exploring the relationship between the political boundaries produced from changing coastlines and sea levels demonstrates how these dynamic material aspects interrupt static political imaginaries. The goal of this analysis is to assess the changes that rising sea levels will have through materialpolitical entanglements at the edges of territory where land and sea meet, in a climatically changing world.

Beginning with coastlines, this paper first addresses the difficulty of collapsing a coastal area into a flat line through a discussion of the theoretical underpinnings of knowing and marking the world through measurement. Indeed, this interface is much more physically blurred and dynamic than is represented politically and legally. This paper builds on emerging ideas in new materialism to re-examine how 'objects' emerge through the technical and material practice of assigning meaning through measurement. Such acts of measurement produce baselines as the demarcating edge where sea level meets land. In this way, the sea is a marker for political borders over the whole globe, but the seas are rising. The political act of measurement is destabilized by unruly natures of the ocean and coasts, illustrating the relative framework of vertical measurements. This unruliness is examined below by exploring the fractal and infinite nature of coasts. Despite these properties, borders fundamental to the international ordering of space are measured from the ocean, using its surface and edges as physical justification for political claims. The fragility of these constructions is revealed by climate change through sea level rise. Practices of drawing fixed political boundaries, in contradiction to the changing material world, manifests in territorial uncertainty, particularly for island and low-lying nations.

\section{THE ACT OF MEASUREMENT}

The littoral boundary where land and sea meet and mix is determined by the height of the ocean's surface, manifesting materially as a realm of coastal features, and produced politically as baselines by means of technical measurement practices. Where these mediums intersect, there are geopolitical motivations to demarcate its edges, and at this convergence borders are traced that formalize the perimeter of a nation's lands and project territoriality outward into the ocean. Yet, this boundary between adjoining mediums is much more physically blurred and dynamic than political borders represent. Change in the height of sea level encroaches on coasts - a change that has both demonstrable material and political impacts - shifting terrestrial and maritime borders inland. Delineating an ephemeral coast is, as Karen Barad describes any act of measurement, 'an instance where matter and meaning meet in a very literal sense' (Barad, 2007, p. 67). Barad uses the term 'phenomena' to indicate that knowing is a material practice by which 'objects' emerge. The act of measuring 
creates a relationship of inseparability between objects, instruments and knower, between ontology and epistemology. Both baselines and sea levels only emerge through such measurements.

Exploring the technical and political construction of the sea's surface as a horizontal plane, and coasts as baselines, becomes increasingly important in the face of geophysical changes that may redraw the geopolitical map. Sea level is a metric used as a reference plane from which to measure terrestrial elevation, aerial altitude and ocean depth, all of which are entangled with notions of nation, territory and borders. The ideas of sea level as a reference plane, and coasts as national borders, are so entrenched that their use as such is implicit, seemingly natural. However, height and depth are relative, and coasts are constantly shifting. They must be constructed as technical objects in order to be employed as stable political markers. The sea is enrolled in territorializations around the globe, requiring extensive technopolitical configuration. The work required through survey and calculation to fabricate static spatial relations from lively natures is one that bisects elements - sea level, a plane where ocean and air froth and effervesce, and at the edges of this plane, the coastal interface where land and sea coalesce and reposition.

Deleuze and Guattari (1987) allude to this within their discussion of the smooth and the striated:

It is as if the sea were not only the archetype of all smooth spaces but the first to undergo a gradual striation gridding it in one place, then another, on this side and that ... only the States were capable of carrying it to completion, of raising it to the global level of a 'politics of science.' A dimensionality that subordinated directionality, or superimposed itself upon it, became increasingly entrenched. This is undoubtedly why the sea, the archetype of smooth space, was also the archetype of all striations of smooth space: the striation of the desert, the air, the stratosphere (prompting Virilio to speak of a 'vertical coastline,' as a change in direction). It was at sea that smooth space was first subjugated and a model found for the laying-out and imposition of striated space, a model later put to use elsewhere. (pp. 479-480)

In the following sections, dimensionality (line, plane, volume) and directionality (lines drawn on the surface projected along a vertical axis), and the politics of the science of global sea level are all examined within the context of rising seas. A historical and theoretical investigation reveals how the material surface of the sea has been enrolled in the technical sciences of triangulating and surveying to measure and mark land, as both a geopotential and a geopolitical plane. Analysis of the fractal nature and nomadism of coasts calls attention to the continuous variation and ambulatory nature of coastal areas, at odds with the static tracings of political borders. Yet, both the political and material importance of sea level cannot be ignored by low-lying communities and nations, as rising seas steal their shores.

\section{THE INFINITE COAST}

Drawing a finite boundary that can define a coastline is complicated by its complex and jagged geography. Not only is the coast line a broad area of shifting and mixing but also the decision about what scale of intricacy to discern inevitably impacts the outcome of the measurement. What has been referred to as the Coastline Paradox describes a conundrum where, due to the fractal properties of such a boundary, the length of a country's coastline will depend on the length of the ruler used. 'A shorter ruler measures more of the sinuosity of bays and inlets than a larger one, so the estimated length continues to increase as the ruler length decreases' (Weisstein, n.d.) (Figure 1). As the mathematician Benoit Mandelbrot, who originally defined this problem, explains, 'the typical coastline is irregular and winding ... coastline length turns out to be an elusive notion that slips between the fingers of one who wants to grasp it ... so ill determined that it is best considered infinite' (Mandelbrot, 1983, p. 25). 


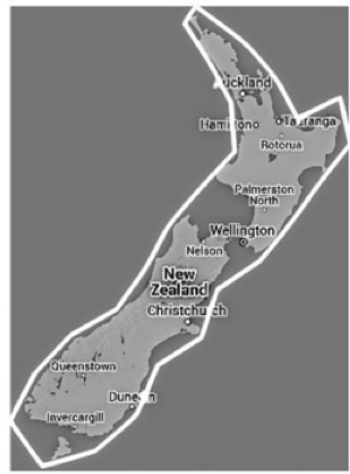

Unit $=100 \mathrm{mi}$, Length $=\mathbf{2 , 6 0 0} \mathrm{mi}$

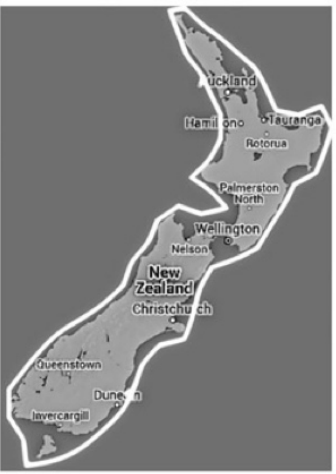

Unit $=\mathbf{5 0} \mathbf{~ m i}$, Length $=2,700 \mathrm{mi}$



Unit $=25 \mathrm{mi}$, Length $=3,000 \mathrm{mi}$

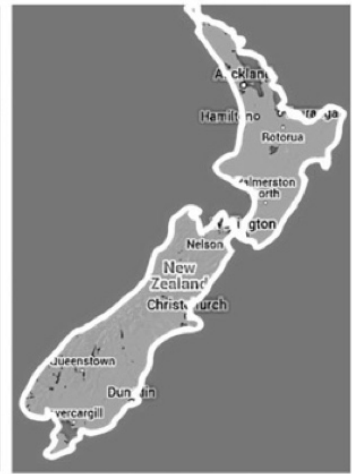

Unit $=5 \mathbf{~ m i}$, Length $=3,300 \mathrm{mi}$

Figure 1. An example of the Coastline Paradox phenomena for New Zealand, where the units of measurement determines the length of coastline measured (Image by author).

This paradox can be explained through an entanglement of instrument and measurement, of subject and object, where the coastline being measured is not a 'thing' in itself, but instead a phenomena (Barad, 2007). A coastal area as a phenomena only becomes an object by engaging with a measurement apparatus, an act that incorporates both the instrument of measurement and the one making the measurement, into the object's being. In this way, a coastline is a process of knowing, a material ontoepistimological engagement emerging through 'a practice of intraacting with the world as part of the world in its dynamic material configuring, its ongoing articulation' (Barad, 2007, p. 379). Mandelbrot seems to be of the same philosophy:

[I]f coastlines are ever to become an object of scientific inquiry, the uncertainty concerning their lengths cannot be legislated away. In one manner or another, the concept of geographic length is not as inoffensive as it seems. It is not entirely 'objective.' The observer inevitably intervenes in its definition. (Mandelbrot, 1983, p. 26)

Mandelbrot makes a further intervention, suggesting coastlines be modelled as fractal curves, 'a coastline is too irregular to be measured directly ... [instead] a sequence of broken lines made of straight intervals, which are curves we know how to handle' (p. 26). Fractals are self-similar so that applying a higher level of magnification will only produce the same replicating pattern, revealing infinite detail (Figure 2). This is the fuzzy space of a coast, where the dimensionality resists being reduced, the area eludes being collapsed to a line. Such a phenomena is realized within Deleuze and Guattari's (1987) spatial philosophy as a smooth space. They also draw on Mandelbrot to engage fractals and recognize them as 'an infinite line or curve with a dimension greater than one, but less than a surface ... [which] provides a general determination for a smooth space' (pp. 486-487). Yet, Mandelbrot (1983) characterizes a fractal curve as 'unbounded and infinitely thin ... [having a] very specific lack of smoothness' (p. 22). A fractal coast is of infinite complexity so that it is realized between one dimension and two, neither line nor plane, and confounds definitions of smooth spatiality. At the fuzzy boundary of a coastline the relationships between land and sea, straight lines and curves, smooth and striated, exhibits the unresolved tensions between them, as the categorization is dependent upon the scales with which they are engaged.

It is important to recognize that, of course, the coast is not a flat space, but a significant region with incredible social and political value. Despite difficulties in defining a coast as a line, the global community of nations negotiated over several decades to determine how to divvy up ocean spaces based on distances from lines drawn at land's end. The strategy to delimit new jurisdictions from shore meant the infinite coastline had 
to be tamed, although we are seeing the unruly sea erode these efforts at new temporal and spatial scales in response to anthropogenic climate change.


Figure 2. A fractal curve at high enough iterations, and with the introduction of some randomness, begins to approximate the shape of a coastline. Images by author, adapted from Chu-Carroll (2007).

\section{LAND'S END}

Multiple techniques and technologies, metrics and coordinates, discourses and laws have been enrolled through history to create a legible geometry and political geography of the world's oceans (Alexander, 1968, 1980; Pearcy, 1959). It has been recognized that the precise and accurate delimitation of a maritime boundary is considerably difficult to conceptualize theoretically or practically implement, for 'maritime boundaries exist 
as virtual objects without visible or tangible demarcation' (Fraser, Collier, \& Leahy, 2013, p. 2). Long before the 1982 United Nations Convention on the Law of the Sea (UNCLOS; United Nations, 1982), lines have been creatively imagined to carve up and parse out ocean space. The Treaty of Tordesillas (1494) bifurcated the sea between the Portuguese Empire and the Crown of Castile per the authority of Pope Alexander VI in the 15th century. In the 17th century, the Cannon Shot Rule granted territorial sovereignty over the coastal sea within three miles of land. The legal concept of a baseline established a 20th- century land-sea division to allocate ocean spaces to coastal nations through the 1958 Convention on the Territorial Sea and the Contiguous Zone, further codified in UNCLOS. Through these treaties, baselines became the technical and political borders of coastal nations, allowing for a uniform line from which to allocate ocean space.

As the increasing height of the sea reshapes coastal areas, it is also shifting these baselines and therefore the borders of coastal territories. While some scholarship has addressed the dire future this will produce for low-lying island nations (Caron, 2009; Carter, 2015; Frost, Hibberd, Nidung, Artack, \& Bourrel, 2016; Ödalen, 2014; Rayfuse, 2009), the widespread political implications for all coastal nations is also important to consider within a broader theoretical context of geopolitics, new materiality and volumetric territories. While the spatial category of territory is often represented as fairly stable, how it is imagined and practised is instead 'produced, mutable, and fluid' (Elden, 2010, p. 812). Political borders frequently use natural features (rivers, mountains, coasts) and assume physical veracity, a matter of factness based on the characteristics of the material landscape. The allusion to a scientific and static border conceals deeply political acts of marking the world through borders and ignores the dynamic of landscapes changing on multiple timescales.

Baselines are defined as the low-water line along the coast as marked on large-scale charts officially recognized by the coastal State ... [a]lternatively, a list of geographical coordinates of points, specifying the geodetic datum, may be substituted' (United Nations, 1982, Article 5). This definition provides the technical information with which to begin partitioning the ocean. In this way the ruler size is standardized, creating a uniform measurement system through the designation of large-scale charts as the metric, usually at a scale on the order of 1:10,000. A combination of methods can be used to determine baselines depending on conditions, but the charts or list of geo- graphical coordinates, with the geodetic datum specified, must be deposited with the Secretary- General of the United Nations. Through this process, a baseline emerges from a coastal area, producing an object from phenomena.

Beyond defining a general scale for measurement, another way the coastal infinity paradox is made manageable is through the use of straight baselines at the unruliest coasts:

[i]n localities where the coastline is deeply indented and cut into, or if there is a fringe of islands along the coast in its immediate vicinity, the method of straight baselines joining appropriate points may be employed in drawing the baseline. (United Nations, 1982, Article 7)

This can be applied for various offending features such as the mouths of rivers and bays, or where 'the presence of a delta and other natural conditions [of] the coastline is highly unstable' (Article 7). This provision alleviates some of the difficulties of approximating this liminal zone and aims to prevent a 'tedious application of rules dealing with the normal baselines ... where their application would produce a complex pattern of territorial seas ... [with] enclaves and deep pockets of non- territorial seas' (United Nations, 1989, p. 18) (Figure 3). Nonterritorial holes within territorial waters - holey spaces, sometimes called 'banana holes' (Norwegian Sea) or 'donut holes' (Arctic Ocean) - arise particularly in cases of archipelago nations or archipelagic shores with a fringe of islands. Straight baselines can smooth and simplify the political patchwork of these striated seascapes.

Once a baseline is determined it constitutes the reference line for measuring the breadth of the maritime jurisdictions defined in the UNCLOS treaty: territorial waters (12 nautical miles (NM) from baseline), contiguous zones (24 NM) and exclusive economic zones (EEZs) (200 NM). 



Figure 3. A demonstration of straight baselines erasing some of the territorial complexities arising from measuring a coastline. Images by author, adapted from United Nations (1989).

These jurisdictions contribute economically productive fisheries, oil and gas fields, and potential undersea mining sites to each coastal nation. Additionally, baselines are the edges that represent the shoreward limit of a nation's terrestrial sovereignty. Not just defining the borders at the surface, these lines also are extended vertically, Virilio's 'vertical coastline', framing territorial volumes of airspace - that is, the airspace superadjacent to the sea surface. Over territorial waters, the atmospheric column above is declared national airspace, where aircraft are required to request permission to enter. Everything seaward is international airspace, where navigation is deemed open to all.

At the coastline the ocean constructs and constantly reshapes the contours of the land, and therefore territorial state. This transmutation is made more conspicuous with rising sea levels. Therefore, changes in the 
height of the sea have a material and political relationship with oceanic, terrestrial and atmospheric borders via multiple lines, surfaces and volumes. As Steinberg and Peters (2015) argue, ' $[\mathrm{t}$ ] he vertical element of volume is all too often abstract and dematerialized; the emphasis on materiality that is typically used to rectify this excess of abstraction tends to repro- duce a sense of matter as fixed and grounded' (p. 247). To understand these complex relationships of the sea and territory, the following section examines the construction of the concept of sea level, outlining the development of producing an abstract plane from a chaotic material ocean.

\section{SEA LEVEL ZERO}

To observe or experience the sea on any human scale is to know it is not particularly level. There- fore, creating a dependable metric based on this medium was not necessarily an obvious nor straightforward undertaking. The historical development of the sea-as-level-plane exhibits oscillating articulations between land and sea imaginaries, each prevailing in turn. There are multiple ways to think about height and numerous choices for the zero-reference plane. Even the term 'sea level' could reference multiple planes, for example, this 'arbitrary zero point could be the mean tide level, mean high water, mean low water' (Theberge, 2005, p. 1) (Table 1). Whereas a horizontal datum is any system used to measure a position on the surface of the Earth (the $x, y$ coordinates of a Euclidean, three-dimensional space, for example, latitude and longitude), a vertical datum measures elevation, altitude or depth $(\mathrm{z}$, the third coordinate needed to determine location in three dimensions). Mean sea level is one type of vertical datum, a temporal average meant to smooth the variability of shorter time scales, including ephemeral wave motion, semi-diurnal tides, meteorological effects and properties of the seawater itself that impact its density, and there- fore height (such as temperature and salinity). Despite these fluctuations in the sea's surface, com- pared with the vertical variations of the Earth's crust, where the deepest trench to the tallest peak spans 19,800 m (65,000 ft), deviations on the sea's surface are comparatively smooth. Therefore, for those interested in vertical measurements, '[t]he almost featureless ocean surface thus has an obvious appeal as an elevation reference' (Douglas, Kearney, \& Leatherman, 2001, p. 3 ). Indeed, tidal datums based on gauge measurements have long been used to establish land-sea divisions. Yet, while tidal gauges represent a vertical datum of the land-sea interface, they are only local measurements.

Table 1. Fort Point, established June 30,1854 at the entrance to the Golden Gate in San Francisco, has produced the longest running series of tidal observations in the Americas. Measurements taken there demonstrate the gamut of vertical datum reference levels (datum measured in $\mathrm{ft}$, available at: https://

tidesandcurrents.noaa.gov/datums.html?id=9414290).

\begin{tabular}{llll}
\hline Datum & Description & Value (ft) & Value (m) \\
\hline MHHW & Mean Higher-High Water & 11.82 & 3.60 \\
MHW & Mean High Water & 11.21 & 3.42 \\
MTL & Mean Tide Level & 9.16 & 2.79 \\
MSL & Mean Sea Level & 9.10 & 2.77 \\
DTL & Mean Diurnal Tide Level & 8.90 & 2.71 \\
MLW & Mean Low Water & 7.11 & 2.17 \\
MLLW & Mean Lower-Low Water & 5.98 & 1.82 \\
NAVD88 & North American Vertical Datum of 1988 & 5.92 & 1.80 \\
STND & Station Datum & 0.00 & 0.00 \\
HAT & Highest Astronomical Tide & 13.24 & 4.04
\end{tabular}


In the United States, the Office of Coast Survey is the oldest national scientific organization, dating to 1807. It was originally established to survey coastlines for the creation of nautical charts. Such work 'reflected larger issues of concern to the young nation: national boundaries, commerce, and defense' (Office of Coastal Survey, 2015). The territorial expression of power manifested by the modern nation requires such surveying towards bounding, classifying, calculating and allocating landscapes and resources (Elden, 2013b). The Coastal Survey's 1857 annual report was the 'first mention of levelling of more than just a local nature' (Point of Beginning, 2011), expanding on local tidal datums to calculate a level sea surface between Nantucket and Martha's Vineyard. Local measurements established at multiple points along the eastern coast of the United States were averaged creating a spatially consistent benchmark plane (Theberge, 2005). This plane was then advanced from the shoreline upriver, to create a fixed and consistent horizontal surface. The calculations continued to move inland establishing the relative height of navigable rivers and the North American Great Lakes to enable maritime commerce. By the turn of the century, there was a network of vertical control stations in the United States, and a reference surface was established by calibrating elevations all over the country to one of five local mean sea levels. This standardization enabled a coherent national jurisdictional and property system and a zero-reference surface from which to determine systematically vertical measurements of elevation and depth.

This new network represented a true geodetic datum in that it extended the reference plane of sea level over a large area. Several adjustments were made to increase the accuracy of the US Vertical Control Network, culminating in the Sea Level Datum of 1929. With the integration of Canada's network, calibrating 'from Maine/New Brunswick to Washington/British Columbia' (Zilkoski, Richards, \& Young, 1992, p. 134), it became an international geodetic network. The Permanent Service for Mean Sea Level (PSMSL), based in Liverpool, England, was established in 1933 to be responsible for the collection and analysis of sea level data from the extending global network of tidal gauges. Mean sea level is meant to correspond to an undisturbed sea, providing a geodetic reference point where the potential energy is the same all over. It is defined as ' $t \mathrm{t}] \mathrm{he}$ average height of the surface of the sea, for all stages of the tide, over a long (usually 19-year) period, being determined from hourly readings of tidal height' (Allaby, 2008, p. 358).

Better instrumentation and calculation methods, and an increased understanding of gravitational and magnetic effects, were used to improve the reckoning of the zero-reference plane. This led to the North American Vertical Datum of 1988 (NAVD 88), which in actuality took from 1977 to 1991 to complete. Sea level was taken out of the name as the datum shifted to using the density of the Earth to determine a geopotential surface. This datum then used only a single tidal datum as a reference point, a gauge in Rimouski, Quebec, Canada. Usurping the sea surface as zero-reference, these control points now measure the acceleration of gravity across the network, which intercedes in alternating land-sea territorializations. Since sea levels are influenced not only by the gravity of the Moon and Sun but also by the subterranean Earth, which exerts local gravity variations based on its uneven magma density, this new measurement system eliminated the hills and valleys of a quasi-level sea surface swayed by local gravity variations.

Advances in space geodesy - the measuring of the shape of the planet and its gravitational field using satellite technology - became the key to improving measurement precision and allowing for the creation of a global vertical datum. Years of satellite measurements have developed a standard reference ellipsoidal model with its origin at the Earth's centre of mass. Creating a geoid datum of the Earth's gravitational field facilitated the accurate representation of an equipotential surface, a surface where the force of gravity is the same everywhere, disconnected from the physical topography of land and sea. However, decoupling a vertical reference plane from the visible surface of the Earth posed its own difficulties. Expressed aptly by Petr Vaníček:

[w] hile the geocentric reference ellipsoid is a very good choice of a global vertical datum for points determined by space techniques, it is not a very good choice for a global vertical datum for practical 
applications because geodetic heights are not physically very meaningful. Height 'consumers' expect to see heights of points at the sea shore to be close to 0 , having been trained to think in terms of 'heights above the sea level'. As we all know, geodetic heights of sea shore points range within almost 200 metres. (Vaníček, 1994, p. 2)

This problem of precision versus practical application was debated by The First International Conference on Geodetic Aspects of UNCLOS in 1992 in an attempt to achieve 'consistency in defining sea coast positions for boundary purposes' (Balasubramania, 1994, p. 2). It was not until 2014 that The International Hydrographic Organization (IHO) designated the use of the World Geodetic System as the universal datum to translate tidal observations with terrestrial reference systems around the world (Bessero, 2014). For scientists working with abstract calculations or at global scales it is appropriate to use a geodetic datum while 'height consumers' working on coastal infrastructure, or navigation projects needing a clear demarcation of the sea's height, would need a datum using a zero sea level. Since the precision of geodetic datums do not always translate well to practical application by more general users, it is useful to examine the application of competing techniques used as vertical measurement apparatuses towards defining the highest peak on Earth.

\section{VERTICALLY RELATIVE}

The importance of sea level as enrolled within a vertical measurement apparatus is substantiated by the continued calculations of the interval between it and the highest peak on Earth. Mountains, such as Mt Everest at over $8 \mathrm{~km}$ high (5 miles), have inspired increasingly technological precision for such measurements. Triangulation techniques used by the Great Trigonometric Survey from the mid-1800s determined its highest peak at $8840 \mathrm{~m}$ above the sea $(29,002 \mathrm{ft})$. Ground-based measurements made using a sophisticated survey network in 1954 registered the official height as $8848 \mathrm{~m}(29,029 \mathrm{ft})$. Just these few metres has significant meaning to those concerned with the measurement of elevation, which is fundamentally entangled in politics. In 1999, Global Positioning System (GPS) technology improved the calculation to $8850 \mathrm{~m}(29,035 \mathrm{ft}$; Ward, 1995), although this is not recognized as the official height by Nepal. The border between Nepal and the Tibet Autonomous Region of China bisects the summit of this peak, making it an important survey point within ongoing regional territorial disputes (Nichenametla, 2017).

Mt Everest, even at the same height as the cruising altitude of a commercial aircraft, still may not be the 'highest' on Earth, depending on what one means to measure and to what end. If distance is instead calculated from the Earth's centre of mass, rather than sea level, this shifts the entire frame of reference. This approach would more closely denote an object's closeness to outer space as opposed to its vertical interval from the sea's surface. This type of calculation is only made possible by satellite geodesy and GPS technologies that allow for some subterranean knowledges regarding the shape and density of the planet's interior. Ecuador's Mt Chimborazo is $2.2 \mathrm{~km}$ (1.36 miles) 'higher' than the illustrious Mt Everest in this formulation (Senne, 2000). Alternatively, Hawaii's Mauna Kea is the world's tallest if measured from base to summit at 10,000 m (33,000 $\mathrm{ft})$, but only $4205 \mathrm{~m}(13,796 \mathrm{ft})$ is above the sea's surface.

Despite any efforts to fix the value of Mt Everest's peak, the devastating earthquake that ravaged Nepal in April 2015 was at first thought to have reduced it by a few centimetres. During the earthquake liquefaction occurred, meaning the ancient lakebed sediments in the valley below the mountain temporarily behaved like a viscous fluid. The fluidity and motion of what we think of as 'solid' ground serves as a reminder that land moves on multiple timescales just as the sea does, shifting in relation to a reference zero-elevation. 


\section{RISING SEAS}

The choice for an appropriate frame of reference is user dependent, a question of epistemology, but it is important to recognize that the ocean's surface, despite not having the sky-high peaks of land, is itself not featureless but a dynamic fluid of constant motion (Steinberg \& Peters, 2015). As a reference plane, it presents its own challenges to the stability of political boundaries. As sea levels rise, changes to mean sea level will alter the relative height of Mt Everest and all other measurements using this reference plane. As noted by international legal scholars:

While there is no universally accepted definition of sea level rise ... sea levels are influenced not only by increase of the masses of water due to glacier melting and their expansion due to warmer temperatures but may also be determined by geological factors such as subsidence or land uplift that may or may not be linked to climate change. (Committee on International Law and Sea Level Rise (CILSLR), 2018, p. 28)

As the reference for important material and scientific metrics shift, the technical and political meanings ascribed to them also face an uncertain future. As mentioned above, the sea's height undergoes changes at multiple timescales. Once shorter term variabilities are corrected for, trends on decadal and geological scales emerge related to anthropogenic emissions and glaciation cycles. Historical tidal gauge data show a Global Mean Sea Level (GMSL) trend of $1.7 \mathrm{~mm}$ increase per year during the 20th century. Since the early 1990s, satellite altimetry has provided nearly global coverage, showing an increased rate of rise to about $3.2 \mathrm{~mm} /$ year in the last two decades (Church et al., 2014). The rate of increase is predicted to accelerate through the 21st century, and 'by 2100, global mean sea level should be on average higher than today in the range of 40-75 cm [16-30 inches]' (Cazenave \& Cozannet, 2013, p. 23).

Within these global trends, there is incredible regional variability in the rate and level of rise related to atmospheric pressure, glacial freshwater and water mass distribution. Material impacts will be substantially uneven, based on physical geography and coastal infrastructure, and includes coastal erosion, inundation, aquifer salination and loss of wetlands. While all these have political implications, due to the methods for claiming ocean jurisdictions, the vertical changes relative to the level of the sea surface can specifically shift sovereign boundaries, and large horizontal shifts can occur from rather small changes in sea level height. As Jonathan Lusthaus explains:

in order to maximise territorial claims, many states have drawn a number of their baselines from features such as low-tide elevations (rocks that emerge only at low tide) and reefs that fringe islands, which are now under threat from sea level rise. ... This means that if a low-tide elevation, located just within what would be the territorial sea, was submerged by sea level rise, up to 12 miles would be lost in the width of the maritime boundaries dependent on this baseline. (Lusthaus, 2010, p. 115)

With regard to EEZs, the loss is potentially much greater. Even the smallest island may generate up to 125,664 $\mathrm{NM}^{2}$ of EEZ area (Sammler, 2016). Many archipelagic islands, which are granted huge EEZs via their scattered island geography, could lose out on large areas of rich marine resources if an islet is submerged or becomes uninhabitable. Islands that are uninhabited, or perhaps become uninhabitable, are considered under UNCLOS as rocks, and '[r]ocks which cannot sustain human habitation or economic life of their own shall have no exclusive economic zone or continental shelf' (Article 121).

Coastal erosion and the submergence of low-lying areas pose legal and technical problems as these processes significantly modify the reference points and lines that determine coastal nations' maritime 
jurisdictions. The ambulatory nature of coastlines does not fit into the broader political systems that value stable borders, exacerbated by accelerated changes due to anthropogenic climate change. One response to the legal and political questions raised by rising seas and shifting base- lines was the formation of two International Law Association Committees: Baselines Under the International Law of the Sea, convened in 2008; and International Law and Sea Level Rise, con- vened in 2012. The Baseline Committee's goal was twofold: to 'identify the existing law on the normal baseline [and] assess if there is a need for further clarification or development of that law' (Committee on Baselines under the International Law of the Sea (CBILS), 2012, p. 1).

Rising seas may submerge some island nations, and the 'resulting deterritorialization will mean, among other things, a total loss of baselines' (CBILS, 2012, p. 30). Recognizing this, it suggested that another committee be established to address issues of statehood, refugee status, resource access and geopolitical stability. The Committee on International Law and Sea Level Rise (CILSR) thus established was tasked with studying the

\begin{abstract}
possible impacts of sea level rise and the implications under international law of the partial and complete inundation of state territory, or depopulation thereof, in particular of small island and low-lying states; and to develop proposals for the progressive development of international law in relation to the possible loss of all or of parts of state territory and maritime zones due to sea level rise, including the impacts on statehood, nationality, and human rights. (CILSLR, 2018, p. 1)
\end{abstract}

The committee recognizes the acceleration of sea level rise and its subsequent inundating impacts as posing 'unprecedented existential challenges' (p. 10) not currently addressed in international law. The submersion of features used as points to define baselines will not only have inordinate impacts on the size of maritime jurisdictions, particularly for archipelagic nations, but also on some island nations' ability to maintain territorial sovereignty over both land and sea.

The committee literature review found two main suggested approaches. One preserves baselines by freezing them at their current location as submitted to UNCLOS, despite the physical changes to coasts. The second proposes that the outer limits of maritime boundaries be preserved even as the baselines shift landward. Both solutions evidence a breaching of UNCLOS as written. Further discussion around maintaining offshore entitlements held concerns that the first approach meant a coastal nation 'could find itself with a claimed baseline that did not reflect reality' by holding claims for which 'physical terrestrial justification had become submerged' (pp.12-13). Such a programme could preserve current marine resource access and avoid perverse incentives 'to build artificial structures on [low water] features in order to maintain their viability as basepoints' (p. 12), recognized as an undue burden for poorer nations. The second approach avoids what the Sea Level Committee calls the 'legal fiction' of submerged baselines, which they find important because the Committee on Baselines determined that baselines are indeed legally ambulatory, tied to physical coastal movements. However, as the baselines follow the waterline inland, if the maritime zones maintained their previous delimitations their size would grow. Ultimately, the committee recommends:

States should accept that, once the baselines and the outer limits of the maritime zones of a coastal or an archipelagic State have been properly determined in accordance with the detailed requirements of the 1982 Law of the Sea Convention, these baselines and limits should not be required to be recalculated should sea level change affect the geographical reality of the coastline. (p. 19)

The question of how to address the potential total loss of a nation's territory, via submersion or uninhabitability, was determined to be a topic for a later conference.

\title{
RISING AND SINKING ISLANDS
}

While the committee suggests the freezing of both baselines and maritime boundaries, this would still need to be adopted into international law, a challenging task in its own right. Many island nations and low-lying states 
will face the most substantial impacts, physically and politically, by rising sea levels. Multiple Pacific Islands, for example, average only a few metres above the sea's surface. Governments and citizens of low-lying nations not only must contend with the immediate material conditions of potentially losing their homes but also must worry about losing their home- lands, languages and identities. If the projected sea level rise reaches its

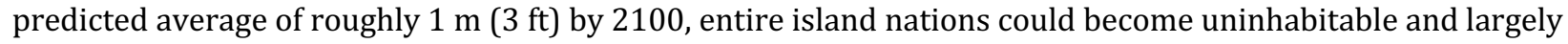
disappear (Horton, Rahmstorf, Engelhart, \& Kemp, 2014).

The Pacific Island nation of Kiribati offers an example of foreboding material consequences of sea level rise.


averages an elevation of about $2 \mathrm{~m}$ ( $6.5 \mathrm{ft}$ ). Past president Anote Tong has been concerned that Kiribati will likely become uninhabitable in 30-60 years because of inundation and contamination of its freshwater supplies (Davenport, 2014). This impending disaster sparked political action and in preparation the government of Kiribati purchased 6000 acres of land in neighbouring Fiji in 2013. They are hoping to alleviate problems of food security and to secure a safe refuge for their population while facing the possible future of becoming a deterritorialized state (Ödalen, 2014). Beyond their sinking elevation, the government is also concerned about offshore claims, as the economy relies heavily on ocean resources. Kiribati is unique in that the archipelagic nation is made up of three separate, highly dispersed island groups, each with its own EEZ. This geography grants the island nation about 3.5 million $\mathrm{km}^{2}$ (1.4 million square miles) of ocean entitlements, in vast contrast to the size of their dry land, which is closer to $800 \mathrm{~km}^{2}$ (310 square miles) of territory.

As international legal scholars debate how to best address sea level rise's impacts, it is still uncertain what will happen to Kiribati's maritime sovereignty as their political boundaries phys- ically erode and sink. Pacific Island nations, through cooperative governance frameworks such as the Pacific Island Forum, have held regional meetings to pre-empt ambulatory baseline discus- sions and advocate for maintaining current boundaries. Kiribati, Marshall Islands and Tuvalu have gone as far as to pass national legislation declaring their maritime jurisdictional boundaries, asserting claims that they hope set a precedent for international law by means of national law, as 'evidence of the development of a regional State practice in the Pacific islands' (CILSLR, 2018, p. 18). In this way, these archipelagic nations seek to express regional agency within the dominant discourses of Small Island Developing States (SIDS) as merely expendable disappearing islands that represent a 'laboratory for global climate change' (Farbotko, 2010, p. 58). The problem of moving coasts and baselines conflict with the fixity of geopolitical borders, and 1 metre of vertical change can make a disproportionately large difference in terms of sovereignty, territory and access to resources. However, submersion beneath the sea's surface is not the only vertical change of import. In the Pacific, and all around the world, land not only sinks beneath sea level but also moves up in relation to it.

Under most conditions, the ocean is much more changeable than solid earth because, unlike the Earth's crust, 'the sea surface displays so little height deviation from the geoid [as] water does not possess any shear strength' (Douglas et al., 2001, p. 5). Yet, the Earth, in its elasticity, changes height, too, in relation to sea level and the geoid. Under the weight of ice sheets, land is com- pressed, and upward velocity and accelerations are still occurring from the last ice age melt. Under current anthropogenic warming trends, places such as Iceland are undergoing glacial iso- static adjustment uplift (the rise of land as it rebounds from the weight of ice sheets) as a result of contemporary anthropogenic rapid ice melt at a rate of $30 \mathrm{~mm} /$ year (Compton, Bennett, \& Hreinsdóttir, 2015), an order of magnitude higher than the rate of sea level rise. In this case, the sea and land are both in vertical motion relative to all three of the zero-reference planes mentioned above.

Surpassing the natural rate of rise of Iceland, entire islands have been constructed from sub- merged coral reefs in less than a year. China has been building seven artificial islands in the South China Sea ${ }^{1}$ by excavating sediment from the sea floor and piling it atop submerged coral reefs. Brought to a higher elevation, not far above the level of the sea's surface, this sediment takes on new meaning, value and materiality by becoming an 
island. By the same logic that the sinking of islands puts their territorial sovereignty in question, the ascension of this sediment above the sea surface projects territoriality through the surrounding land, sea and air. While man-made islands are explicitly defined in UNCLOS as to not incur their own maritime jurisdictions, building these artificial islands stake more than a rhetorical claim, indeed: ' $[\mathrm{t}] \mathrm{o}$ alter the ground does not simply alter the present truth: it alters the record of past truths, depositing new layers of meaning as it obscures old ones' (Rice, Tyner, Munro-Stasiuk, Kimroy, \& Sirik, 2016, p. 3). Beyond just a metaphorical flag planting, these islands pose more than symbolic claims: they provide material support structures, such as ports, airstrips, and communication and surveillance infrastructure. This allows patrolling of the entire territorial volume, beneath the sea, the sea's surface and the airspace above. As such, China has declared an Air Defense Identification Zone (ADIZ), not just over their maritime jurisdictions but also overlapping other nation's maritime jurisdictions. These vertical projections extend the political plane of sea level, and its changing borders, up into the atmosphere.

\section{CONCLUSIONS}

Elden's work on vertical geopolitics recognizes that '[g]eopolitics has tended to become conflated with global politics or political geography writ large. But could we turn this back to thinking about land, earth, world rather than simply the global or international?' (Elden, 2013a, p. 49). His argument, that geo-metrics should be revived as a study beyond just abstract geometry, but as a way to study the 'calculative strategies turned towards land, terrain and territory', is augmented with the significant influence that the ocean has in territorializing techniques, of both land and sea. Given the prominence of the ocean, covering $70 \%$ of the Earth's surface, this paper has critically examined its importance in global politics, both geopolitically and geomaterially. Making explicit the expertise, technology and physical characteristics that construct sea level as a geophysical and geopolitical plane demonstrates how territorial boundaries are produced and reproduced in relation to it. These examinations of the historical creation of a level sea show how physical geographical features are normalized as geopolitical borders and extraterritorial volumes transition into national territories, but also how these emergent borders are challenged by the materiality of a dynamic earth, particularly at elemental interfaces. Specifically attending to the conceptual and performative aspects of bounding territory, and the extension of this territorialization from points to lines, and surfaces to volumes, it becomes clear that dominant flat discourses of geopolitics cannot capture the material-political-technical assemblages rewriting and remaking these spaces.

Sea level rise is already occurring, and more rise cannot be averted. There are choices being made now that impact whether the direst ranges of climate change will be realized. How high the levels rise depends on current carbon dioxide emission levels, determining the intensity of physical impacts. Current discussions amongst international legal scholars will influence how to reconfigure relationships between the material and political aspects of sea level and its existential implications for many island and low-lying nations. David Caron frames the issue as a 'legal feed- back' which, 'unlike a physical feedback, does not accelerate or mitigate the underlying process of climate change itself. Rather, it accelerates or mitigates the damage that will be felt as a consequence of any level of climate change' (Caron, 2009, p. 2).

As established in the cases of Mt. Everest, Kiribati and China's artificial islands, the difference in elevation of just a couple metres above or below the sea's surface - particularly the transformation of submerged to super-adjacent, or vice versa - is a powerful signifier in a physically and leg- ally ambiguous future. Recognizing the social construction of land-sea boundaries makes it clear that it is not inevitable that sinking islands become deterritorialized states. Territory as a category has undergone many transformations and reimaginings 
(Elden, 2013b). Tracking the historical methods and instrumentations of accounting for height presents the alternating visions of surveying land from the sea and sea from land, making explicit the relational terms of height, depth and territory. While the concept of sea level is not being disputed politically, the marks it makes on the world as baselines and borders which are derived from these markers are. In a climatically changing world of sea level rise, this is an important topic for social scientists, and especially geographers, to engage theoretically. Understanding this mode of organizing spatial expressions of territory offers insights into the emerging geographies of non-terrestrial spaces, which become increasingly important as various claims are made on increasingly difficult and distant places.

\section{ACKNOWLEDGEMENTS}

An early version of this paper was formulated as a dissertation chapter for which the author thanks members of the committee: Jeffrey Banister, Steven Yool, Vincent Del Casino, Philip Stein- berg and Sarah Moore. A special thanks to the supportive community at the University of Arizona School of Geography \& Development, especially members of the Tucson Aquatic Enthusiast Society. The author acknowledges the encouragement and critique from organizers and participants at the Shifting Baselines, Altered Horizons: Politics, Practices, and Knowledge in Environ- mental Science and Policy workshop held at the Max Plank Institute for the History of Science in Berlin, Germany, 2018. The author is also grateful to the two anonymous reviewers and editors for constructive feedback on earlier drafts.

\section{NOTE}

1. Cuarteron Reef, Fiery Cross Reef, Gaven Reef, Hughes Reef, Johnson Reef, Mischief Reef and Subi Reef. ORCID

\section{REFERENCES}

Alexander, L. M. (1968). Geography and the Law of the Sea. Annals of the Association of American Geographers, 58 (1), 177197.

Alexander, L. M. (1980). The new geography of the world's oceans before and after law of the sea. Columbia Journal of World Business, 15(4), 6-17.

Allaby, M. (2008). A dictionary of earth sciences (Fourth ed.). New York, NY: Oxford University Press.

Balasubramania, N. (1994). Definition and realization of a global vertical datum (Tech. Rep. No. OSU Report No. 427). Ohio State University: Department of Geodetic Science and Surveying.

Barad, K. (2007). Meeting the universe halfway: Quantum physics and the entanglement of matter and meaning. Durham, NC: Duke University Press.

Bessero, G. (2014). Proposed revisions to IHO resolutions on tides, water levels and tidal publications (Vol. IHB File No. S3/1400; Tech. Rep. Monaco: International Hydrographic Organization.

Caron, D. D. (2009). Climate Change, Sea Level Rise and the Coming Uncertainty in Oceanic Boundaries: A Proposal to Avoid Conflict. In S.-Y. Hong, \& J. M. Van Dyke (Eds.), Maritime boundary disputes, settlement processes, and the Law of the Sea. Leiden: Brill | Nijhoff.

Carter, A. (2015). No man is an island: Low-lying nations' economic security through a fixed exclusive economic zone in the wake of sea-level rise. Global Environmental Democracy Project.

Cazenave, A., \& Cozannet, G. L. (2013). Sea level rise and its coastal impacts. Earth's Future, 2, 15-24. Chu-Carroll, M. C. (2007, July 17). Fractal curves and coastlines. Retrieved from http://scienceblogs.com/

goodmath/2007/07/17/.

Church, J., Clark, P., Cazenave, A., Gregory, J., Jevrejeva, S., Levermann, A., ... Unnikrishnan, A. (2014). Sea Level Change. In Stocker et al. (Eds.), Contribution of Working Group I to the Fifth Assessment Report of the 
Intergovernmental Panel on Climate Change. Cambridge: Cambridge University Press. U. K., and New York. Committee on Baselines under the International Law of the Sea. (2012). Conference report. 75th Conference of the International Law Association, Sofia, Bulgaria. International Law Association.

Committee on International Law and Sea Level Rise (CILSR). (2018). Conference Report. 78th Conference of the International Law Association, Sydney, Australia. International Law Association.

Compton, K., Bennett, R. A., \& Hreinsdóttir, S. (2015). Climate-driven vertical acceleration of Icelandic crust measured by continuous GPS geodesy. Geophysical Research Letters, 42(3), 743-750.

Davenport, C. (2014, March 27). Rising seas. Retrieved from www.nytimes.com/interactive/2014/03/27/world/ climaterising-seas.html.

Deleuze, G., \& Guattari, F. (1987). A thousand plateaus: Capitalism and schizophrenia. Minneapolis, MN: University of Minnesota Press.

Douglas, B. C., Kearney, M. S., \& Leatherman, S. P. (eds.). (2001). Sea level rise history and consequences (Vol. 75). Cambridge, MA: Academic Press.

Elden, S. (2010). Land, terrain, territory. Progress in Human Geography, 34(6), 799-817.

Elden, S. (2013a). Secure the volume: Vertical geopolitics and the depth of power. Political Geography, 34, 35-51.

Elden, S. (2013b). The birth of territory. Chicago, IL: The University of Chicago Press.

Elden, S. (n.d.). Dynamic territories. Retrieved from https://icelawproject.org/reflections-2/dynamic-territories/.

Farbotko, C. (2010). Wishful sinking: Disappearing islands, climate refugees and cosmopolitan experimentation. Asia Pacific Viewpoint, 51(1), 47-60.

Fraser, R., Collier, P., \& Leahy, F. (2013). Positioning maritime boundaries with certainty - a rigorous approach. Proceedings of the International Conference on Addressing Difficult Issues in UNCLOS.

Frost, R., Hibberd, P., Nidung, M., Artack, E., \& Bourrel, M. (2016). Redrawing the map of the Pacific. Marine Policy, 95, 302310.

Horton, B. P., Rahmstorf, S., Engelhart, S. E., \& Kemp, A. C. (2014). Expert assessment of sea-level rise by ad 2100 and ad 2300. Quaternary Science Reviews, 84, 1-6.

Houghton, K. J., Vafeidis, A. T., Neumann, B., \& Proelss, A. (2010). Maritime boundaries in a rising sea. Nature Geoscience, 3(12), 813-816.

Lusthaus, J. (2010). Shifting sands: Sea level rise, maritime boundaries and inter-state conflict. Politics, 30(2), $113-118$.

Mandelbrot, B. B. (1983). The fractal geometry of nature. New York, NY: W. H. Freeman and Company.

Nichenametla, P. (2017, August 13). China standoff stalls Indo-Nepal plan to remeasure Everest height. The Times of India. Retrieved from https://timesofindia.indiatimes.com.

Ödalen, J. (2014). Underwater self-determination: Sea-level rise and deterritorialized small island states. Ethics, Policy \& Environment, 17(3), 225-237.

Office of Coastal Survey. (2015). History of coast survey. Retrieved from http://www.worldheritage.org/articles/ Coast_Survey.

Pearcy, G. E. (1959). Geographical aspects of the law of the sea. Annals of the Association of American Geographers, 49 (1), 1-23.

Point of Beginning. (2011, July 31). Establishing sea level datum. Retrieved from https://www.pobonline.com/ articles/89317-web-exclusive.

Rayfuse, R. G. (2009). W(h)ither Tuvalu? International law and disappearing states. UNSW Law Research Paper,

Rice, S., Tyner, J. A., Munro-Stasiuk, M., Kimroy, S., \& Sirik, S. (2016). Making land to make life: Island-building in the South China Sea and the biopolitics of geophysical transformation. The Geographical Journal, 182(4), 444-448.

Sammler, K. (2016). The deep Pacific: Island Governance and Seabed Mineral Development. In Stratford (Ed.), Island geographies: Essays and conversation (pp. 10-31). New York, NY: Routledge.

Senne, J. H. (2000, May). Did Edmund Hillary climb the wrong mountain? Professional Surveyor Magazine. 20(5). https://archives.profsurv.com/magazine/article.aspx?i=589

Steinberg, P. E., \& Peters, K. (2015). Wet ontologies, fluid spaces: Giving depth to volume through oceanic thinking. Environment and Planning D: Society and Space, 33, 247-264.

Theberge, Jr., A. E. (2005). 150 years of tides on the western coast: The longest series of tidal observations in the Americas. Silver Spring, MD: U.S. Dept. of Commerce, National Oceanic and Atmospheric Administration, National Ocean Service, Center for Operational Oceanographic Products and Services.

United Nations. (1982, December 10). United Nations convention on the Law of the Sea. (A/Conf.162/122). Retrieved from http://www.un.org/depts/los/conventionagreements/conventionoverviewconvention.htm 
United Nations. (1989). Baselines: An examination of the relevant provisions of the United Nations Convention on the Law of the Sea. New York, NY: Office for Ocean Affairs and The Law of the Sea.

Vaníček, P. (1994). On the global vertical datum and its role in maritime boundary demarcation. Proceedings of International Symposium INSMAP 94, 243-250.

Ward, M. (1995). The height of Mount Everest. The Alpine Journal, 30-33.

Weisstein, E. W. (n.d.). Coastline paradox. Retrieved from http://mathworld.wolfram.com/CoastlineParadox.html.

Zilkoski, D. B., Richards, J. H., \& Young, G. M. (1992). Results of the general adjustment of the North American Vertical Datum of 1988. Surveying and Land Information Systems, 52(3), 133-149. 